\title{
Analysis of spatial diversity of sal (Shorea robusta Gaertn.f) forests using neighbourhood-based measures
}

\author{
M.M. Rahman ${ }^{1,4}$, A. Nishat ${ }^{2}$, G.M.M. Rahman ${ }^{3}$, H. Ruprecht ${ }^{1}$ and H. Vacik ${ }^{1}$ \\ ${ }^{1}$ Institute of Silviculture, Department of Forest and Soil Sciences, University of Natural Resources and Applied Life \\ Sciences, Peter Jordan-Straße 82, A-1190 Vienna, Austria \\ ${ }^{2}$ The World Conservation Union (IUCN), Bangladesh Country Office, House-11, Road-138, Gulshan-1, \\ Dhaka 1212, Bangladesh \\ ${ }^{3}$ Department of Agroforestry, Bangladesh Agricultural University, Mymensingh 2202, Bangladesh \\ ${ }^{4}$ Corresponding author.E-mail: mizan.rahman@boku.ac.at,mizan_peroj@yahoo.com,Tel.: 0043-1-47654-4075, \\ Fax: 0043-1-47654-4092
}

Keywords: Aggregation, Dispersion, Homogeneity, Reference trees.

Abstract: The study presents an analysis of spatial and structural diversity of Sal (Shorea robusta), the dominant species of sal forests in Bangladesh by using a neighbourhood analysis approach. The simple field method permits relatively unskilled persons to collect data. Most of the indices can be calculated in the field and the data analysis is comparatively easy. Therefore, the applicability of the method was tested by using different setting of reference trees compared with the full sampling for each plot in the Madhupur sal forests. The results indicate that a group of one reference tree and its four neighbours can be used efficiently to describe the spatial and structural diversity in homogeneous young forests at low costs and in short time. The indices can be easily interpreted allowing quantitative comparisons between different types of forest stands. Sal can be considered as the dominant and comparatively faster growing species than other associate species.

\section{Introduction}

The sal forests of Bangladesh belong to the category of tropical moist or dry deciduous forest (Gain 1998). In Bangladesh, it is one of the three major forest resources (other types are tropical evergreen and coastal forest), which covers about $32 \%$ of the forested land (Banglapedia 2006). Sal (Shorea robusta, Dipterocarpaceae) is the dominant species of these forests, which are comprised of pure and mixed stands (Ismail and Mia 1973). These forests have a high economical and ecological significance in the central part of Bangladesh. Sal forests have also ethnic and cultural values in Bangladesh as ethnic communities (tribal people) live in these forests and, their livelihood and culture are directly related to them. Few studies on floristic diversity (incomplete list of plants) can be found, but no systematic studies on structural and spatial diversity have been done so far (Alam 1995, Rahman et al. 2007a).

Spatial stand structure is an important factor in determining habitat, species diversity and management practices. The structural diversity generally considers species composition, horizontal and vertical variation within the forests and on the other hand, spatial diversity considers these characteristics in space or arrangement of these dimensions in relation to each other. The structural diversity can be assessed by the spatial diversity as well. In the past, studies relating to spatial aspects were not comprehensive, cost effective or easy. Lund pair correlations involve tree coordinates (Stoyan and Stoyan
1992, Pretzsch 2001, Pommerening 2002) requiring large databases which may not always be available. Distant dependant indices proposed by Clark and Evans (1954) or Pielou (1977) can give a snap shot of the forest structure by describing the variety of spatial arrangements (Zenner and Hibbs 2000). Single tree-based variables or neighbourhood-based parameters or 'measure of surround' (Gadow et al. 1998, Staupendahl 2001) can be used to provide a comprehensive description of the spatial structure of a forest. The neighbourbased variables can be used in quick assessment of large forests (Pommerening 2002, Graz 2006). These parameters are used to quantify the regularity of neighbours position, size and interspersion with reference trees. Other than European scientists, Graz (2006) used these variables in dry savana woodland of Africa and Aguirre et al. (2003) experimented in Mexican forests successfully for assessing spatial diversity. Recent studies evaluated the applicability or the advantages of using neighbourhood-based variables for the analysis of structural diversity. However, a study on the sample size (suitable number of reference trees and neighbouring trees) and the importance of choosing an appropriate setting for the study design for assessing the spatial diversity has not been tested so far. Our study aims to assess the applicability of these neighbourhood-based variables in the sal forests of Bangladesh, to analyse the spatial diversity of the dominant species for a better understanding of the ecology of these forests and finally to find out a suitable setting for the neighbourhood analysis. 


\section{Materials and methods}

\section{Study sites}

The study was carried out at Madhupur, the largest area of sal forests in Bangladesh during November 2006 - January 2007 . These forests are intercepted by numerous depressions in the form of long and narrow valleys called 'Baid' locally, which are cultivated for agricultural crops, especially rice. For the presence of this 'Baid', continuous cover forests cannot be found in this region. Geographically it is located at $23^{\circ} 50^{\prime}-24^{\circ} 50^{\circ}$ North latitude and $89^{\circ} 54^{\circ}-90^{\circ} 50^{\prime}$ ' East longitudes. The soil belongs to the bio-ecological zone of Madhupur sal Tract, which is above the normal flood level (Nishat et al. 2002). The soils are moderately to strongly acidic in reaction (Richards and Hassan 1988), the annual rainfall is 2030-2290 $\mathrm{mm}$ while the maximum temperature is $34^{\circ} \mathrm{C}$ and minimum is $11^{\circ} \mathrm{C}$ (Islam et al. 2007). Webb and Sah (2003) classified sal forests as natural, successional (forest regenerated naturally after clear cutting) and plantation sal. We selected two stands for this study in the successional forests of the same age. One stand was at Rasulpur and the other stand at Rajabari area in the Madhpur sal forests. Both forests are highly dominanted by sal.

\section{Sampling}

Due to the presence of 'Baid', it was not possible to establish all plots on a regular grid. Therefore, the plots were randomly selected on transects with a minimum distance of $100 \mathrm{~m}$ between them. Thirty circular plots were established in Rasulpur as well as in Rajabari. The area of each plot was $300 \mathrm{~m}^{2}$ having $9.77 \mathrm{~m}$ radius. In each plot, we selected $3 \mathrm{sal}$ trees termed as reference trees. To reduce bias from the selection process of a reference tree, the first reference tree was taken as the nearest one from the centre, the second reference tree was taken as the nearest one from the middle point of the radius and finally the third reference tree was chosen as the most distant sal from the centre of the plot (Fig. 1). For each reference tree, the four nearest neighbours were chosen for neighbourhood analysis. In this context, the reference tree with its four neighbours was termed as 'group of five' (G5).

In each plot, we recorded all trees $(\mathrm{dbh} \geq 5 \mathrm{~cm})$ according to species name, dbh and height of each trees. For the neighbourhood variables, we measured dbh and height of each reference tree and four neighbouring trees. We classified the angle between every two neighbours in clock-wise direction in the field whether this angle was smaller or bigger than $90^{\circ}$.

\section{Data analysis}

For characterizing spatial diversity, we calculated four indices for each reference group and for each plot. For the subsamples of the 3 groups ( $1 \mathrm{G} 5$ or 5 trees, $2 \mathrm{G} 5$ or 10 trees and $3 \mathrm{G} 5$ or 15 trees per plot), the indices were calculated separately. SPSS ${ }^{\circledR}$ was used to analyze the correlations among different variables and to test the mean values for significant differences at a significance level of $5 \%$.

\section{Contagion}

The contagion (Gadow et al. 1998, Staupendahl 2001) describes the degree of regularity of the spatial distribution of the four trees nearest to a reference tree $i$ (Fig. 2). $W_{i}$ is based on the classification of the angles $\alpha_{j}$ between each pair of the four neighbours. Assuming complete regularity of the positions of the four nearest neighbours around a reference tree, the expected standard angle $\alpha_{0}$ would be equal to $360^{\circ} / 4$ $=90^{\circ}$. In case of neighbours, $w_{i j}$ can be visually assessed in the field by comparing $\alpha_{j}$ with $\alpha_{0}$. A quick decision can be made in the forest on whether $\alpha_{j}$ is smaller than or equal to $90^{\circ}$ or not.

$$
\begin{aligned}
& W_{i}=\frac{1}{4} \sum_{j=1}^{4} w_{i j} \quad W_{i} \in[0,1] \\
& w_{i j}=\left\{1, \text { if } \alpha_{j}<\alpha_{0} ; 0 \text { otherwise }\right\}
\end{aligned}
$$

$W_{i}=0$ indicates that the neighbouring trees are positioned in a regular manner, whereas $W_{i}=1$ indicates an irregular or clumped distribution. With four neighbours, there are five possible values $(0,0.25,0.50,0.75$ and 1$)$ that $W_{i}$ can assume. The average contagion value may be classified as 'regular', 'random' and 'clumped' (Gadow et al. 1998). The mean contagion value greater than 0.6 can be considered as 'clumped', those with values between 0 and 0.5 indicate 'regular' tree distributions, and between 0.5 and 0.6 are 'random' (Albert 1999).

\section{Species mingling}

The corresponding single tree variable to Pielou's coefficient of segregation, known as mingling $\left(M_{i}\right)$, gives the proportion of the $n=4$ nearest neighbours $j(j=1 \ldots . n)$ of the $i$ th reference tree which do not belong to the same species as the reference tree $i$ :

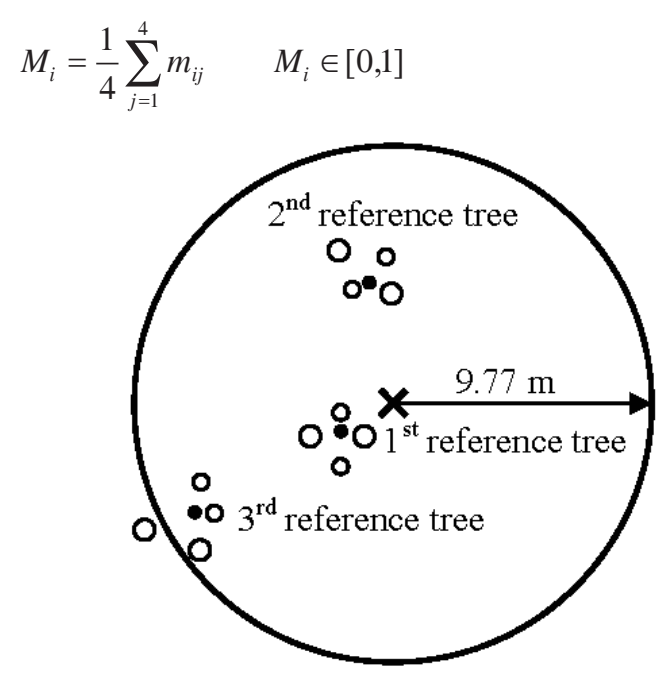

Figure 1. A sample plot with 3 reference trees and their neighbours. 
$m_{i j}=\{1$, if reference tree $i$ and neighbouring tree $j$ are of different species; 0 , otherwise $\}$. In case of 4 neighbours, $M_{i}$ can assume 5 possible values $(0.0,0.25,0.50,0.75$ and 1.00$)$. The arithmetic mean of $M_{i}$ for a particular species of reference tree $\left(M_{S p}\right)$ provides a measure of the degree of interspersion of the species in the area. Values close or equal to 1 indicate a high degree of mingling, i.e., trees of the reference species do not occur in a clumped manner. On the other hand, values near or equal to 0 indicate a low degree of mingling and a high aggregation, i.e., reference tree and all neighbours are of the same species. $1-M_{S p}$ approximates the proportion, $P$ of that species in the stand.

\section{Size dominance}

In addition to the mingling of species described above, the interspersion of tree dominance in size is quantified on the basis of diameter $\left(D_{i}\right)$ and height $\left(H_{i}\right)$ using the 'measure of surrounding' described by Hui et al. (1998), which is applied analogously to the mingling index:

$S_{i}=\frac{1}{4} \sum_{j=1}^{4} s_{i j} \quad S_{i} \in[0,1]$

$s_{i j}=\{1$, if tree $j$ is thicker/higher than the sample tree $i ; 0$, otherwise $\}$. With four neighbours, five possible values $(0$, $0.25,0.50,0.75$ and 1$)$ can be calculated for $S_{i}$. The average value of $S_{i}=0$ indicates that all 4 neighbouring trees are smaller in size than the reference tree where the value 0 indicates that all neighbouring trees are taller or have a larger diameter than the reference trees.

The size dominance $S_{i}$ is interpreted as diameter dominance $D_{i}$ and height dominance $H_{i}$ in a similar way.

$D_{i}=\frac{1}{4} \sum_{j=1}^{4} d_{i j} \quad D_{i} \in[0,1]$ $d_{i j}=\{1$, if tree $j$ is thicker than the sample tree $i ; 0$, otherwise $\}$

$H_{i}=\frac{1}{4} \sum_{j=1}^{4} h_{i j} \quad H_{i} \in[0,1]$

$h_{i j}=\{1$, if tree $j$ is higher than the sample tree $i ; 0$, otherwise $\}$

\section{Size differentiation index}

The singletree diameter differentiation variable, $S_{i j}$, gives the size difference of neighbouring trees on a continuous scale and describes the spatial distribution of tree sizes (Füldner 1995, Pommerening 1997, 2002). For the $i$ th reference tree and its $n=4$ nearest neighbour $j(j=1 \ldots n)$ the diameter differentiation $S_{i j}$ is defined as:

$$
S_{i j}=1-\frac{\min \left(\text { size }_{i}, \text { size }_{j}\right)}{\max \left(\text { size }_{i}, \text { size }_{j}\right)} \quad S_{i} \in[0,1]
$$

The value of $S_{i j}$ increases with increasing average size difference between neighbouring trees. $S_{i j}=0$ means that neighbouring trees have an equal size. This index is based on pairs of reference trees - first, second, third or fourth nearest neighbour tree. The size differentiation can be classified as diameter differentiation $D_{i j}$ and height differentiation $H_{i j}$ :

$$
\begin{aligned}
& D_{i j}=1-\frac{\min \left(d b h_{i}, d b h_{j}\right)}{\max \left(d b h_{i}, d b h_{j}\right)} \quad D_{i} \in[0,1] \\
& H_{i j}=1-\frac{\min \left(\text { height }_{i}, \text { height }_{j}\right)}{\max \left(\text { height }_{i}, \text { height }_{j}\right)} \quad H_{i} \in[0,1]
\end{aligned}
$$

Size differentiation values can be interpreted as follows (Pommerening 2002):

\section{Contagion}

regular clumped

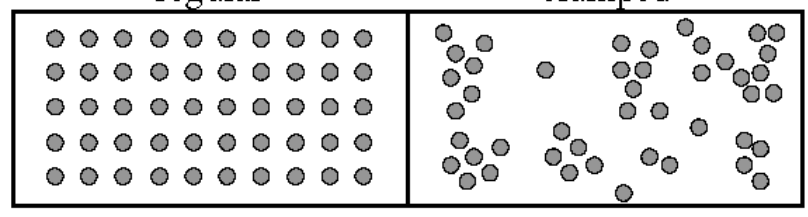

high

low

\begin{tabular}{|llllllllll|lllllllllllllll}
\hline 0 & 0 & 0 & 0 & 0 & 0 & 0 & 0 & 0 & 0 & 0 & 0 & 0 & 0 & 0 & 0 & 0 & 0 & 0 & 0 \\
0 & 0 & 0 & 0 & 0 & 0 & 0 & 0 & 0 & 0 & 0 & 0 & 0 & 0 & 0 & 0 & 0 & 0 & 0 & 0 \\
0 & 0 & 0 & 0 & 0 & 0 & 0 & 0 & 0 & 0 & 0 & 0 & 0 & 0 & 0 & 0 & 0 & 0 & 0 & 0 \\
0 & 0 & 0 & 0 & 0 & 0 & 0 & 0 & 0 & 0 & 0 & 0 & 0 & 0 & 0 & 0 & 0 & 0 & 0 & 0 \\
0 & 0 & 0 & 0 & 0 & 0 & 0 & 0 & 0 & 0 & 0 & 0 & 0 & 0 & 0 & 0 & 0 & 0 & 0 & 0
\end{tabular}

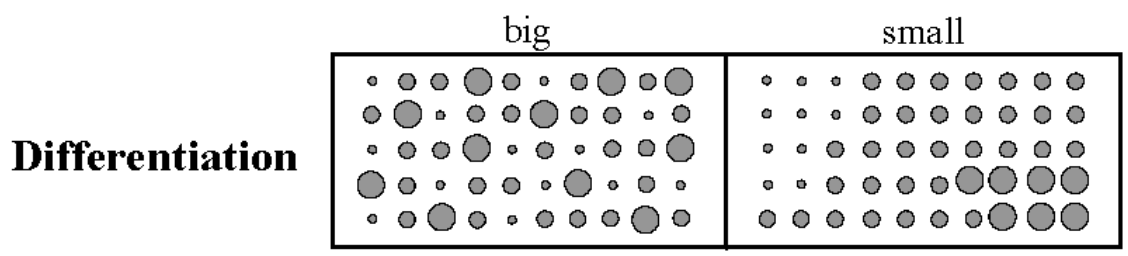

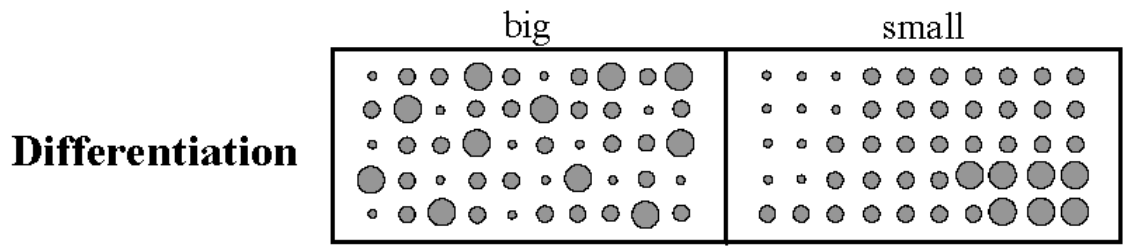

Figure 2. Aggregation, dispersion and size differentiation of trees in a forest. 
Small differentiation: Comprises average values $0.0-0.3$ (the average size of a neighbour is $0-30 \%$ larger or smaller than that of a reference tree)

Average differentiation: Comprises average values 0.3-0.5 (the average size of a neighbour is $30-50 \%$ larger or smaller than that of a reference tree)

Big differentiation: Comprises average values 0.5-0.7 (the average size of a neighbour is $50-70 \%$ larger or smaller than that of a reference tree)

Very big differentiation: Comprises average values $0.7-1$ (the average size of a neighbour is $50-70 \%$ larger or smaller than that of a reference tree)

\section{Results}

\section{Contagion and mingling}

The mean contagion values of Rajabari stand across 1G5 (5 tree), 2G5 (10 tree) and 3G5 (15 tree) per plot were 0.67, 0.66 and 0.66 , respectively, indicating a 'clumped' dispersion of trees in all 3 cases; whereas at Rasulpur, the contagion values were $0.50,0.50$ and 0.51 respectively, indicating a 'random' dispersion of trees (Table 2). The number of reference trees per plot did not affect the results and interpretation of tree dispersion significantly at both stands.

The mean mingling values were $0.04,0.05$ and 0.05 , respectively, using 1G5, 2G5 and 3G5 per plot at Rajabari. Each of the mean values was near to 0 indicating a very low 'degree of mingling' or 'very high aggregation' of sal. At Rasulpur, the average mingling values for the $1 \mathrm{G} 5,2 \mathrm{G} 5$ and $3 \mathrm{G} 5$ per plot were $0.18,0.20$ and 0.22 , respectively, indicating a low 'degree of mingling' or 'high aggregation' of sal as well (Table 2). To find out the proportion of sal from the mingling within the stand we calculated the value of $1-M_{S a l}$. The mean values of $1-M_{S a l}$ of Rajabari forest were $0.96,0.95$ and 0.95 , respectively, using $1 \mathrm{G} 5,2 \mathrm{G} 5$ or $3 \mathrm{G} 5$ per plot. Considering all trees within a sample plot, the average proportion of sal was 0.94 at Rajabari stand. For Rasulpur, the mean values of $1-M_{\text {sal }}$ were $0.82,0.80$ and 0.78 , respectively, where the proportion of sal was 0.81 considering all trees from the plots. There was no significant difference of the proportion of sal across different sample sizes (Table 2). There was a positive linear correlation found between the total density of sal or the proportion of sal and the contagion value. With the increase of the stem number of sal trees and the overall proportion of sal, the value for the contagion index increased (Table 4).

\section{Size dominance and size differentiation}

The mean values of the diameter dominance were 0.43 , 0.45 and 0.49 respectively for the $1 \mathrm{G} 5,2 \mathrm{G} 5$ and $3 \mathrm{G} 5$ samples, which indicated that $43 \%, 45 \%$ and $49 \%$ of the neighbours had a larger diameter at breast height than the reference trees at Rajabari. Similarly, $46 \%, 46 \%$ and $43 \%$ of the neighbours were larger at Rasulpur (Table 2).
Using the indices based on the $1 \mathrm{G} 5,2 \mathrm{G} 5$ and $3 \mathrm{G} 5$ per plot the height dominance was calculated as $0.45,0.44$ and 0.47 for Rajabari, where $0.36,0.42$ and 0.38 for Rasulpur (Table 2). The mean diameter differentiation of Rajabari forests were $0.15,0.16$ and 0.16 , indicating a 'small' differentiation using $1 \mathrm{G} 5,2 \mathrm{G} 5$ and $3 \mathrm{G} 5$ per plot, where the mean diameter differentiation was $0.16,0.17$ and 0.17 indicating a 'small' differentiation also at Rasulpur. Similarly, the height differentiation was 'small' at both stands across different sample sizes (Table 2). The sal-sal diameter and height differentiation were more homogeneous in both stands than sal-other species (Table 3). There was no statistically significant difference found for the mean size dominance and differentiation for 1G5, 2G5 and 3G5 per plot in each stand (Table 2).

The mean diameter and height of sal were larger than those of the other species at both stands (Table 1). The diameter distributions were more homogeneous across different sample sizes (Fig. 4) than the height distributions (Fig. 5). No noticeable changes occurred in both diameter and height distributions across different sample sizes (Figs. 4-5).

\section{Homogeneity or heterogeneity of the distribution of indices within and between the forest stands for using different sample sizes}

There were no statistically significant differences in mean values for any of the indices calculated within each

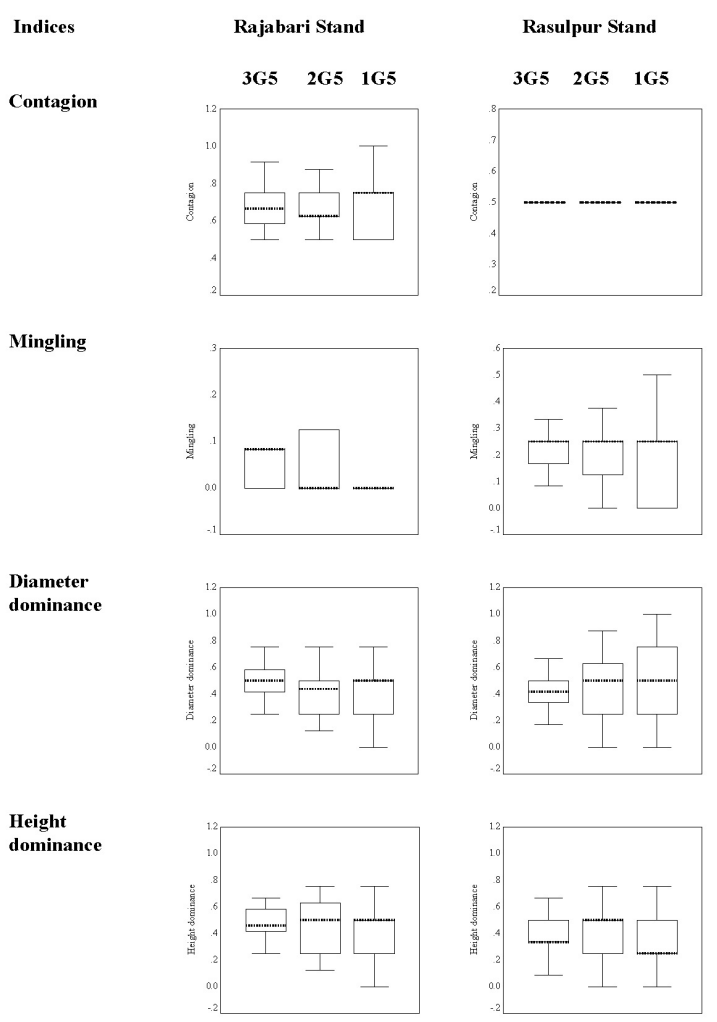

Figure 3. Boxplots showing medians, quartiles, maximum and minimum values of major indices across different sample sizes in Rasulpur and Rajabari forest stands. 
Table 1. Basic information (Mean $\pm \mathrm{SD}$ ) of the investigated forests based on data from the full sampling of all trees per plot.

\begin{tabular}{lllllll}
\hline Stand & Tree & Density of & DBH of & DBH of other & Height of & Height of other \\
& $(\mathrm{N} / \mathrm{plot})$ & Sal(N/ha) & Sal $(\mathrm{cm})$ & sp. $(\mathrm{cm})$ & Sal $(\mathrm{m})$ & $\mathrm{sp} .(\mathrm{m})$ \\
\hline Rajabari & $56.7 \pm 4.3$ & $1784.2 \pm 128.7$ & $7.4 \pm 2.0$ & $6.3 \pm 1.2$ & $5.9 \pm 1.7$ & $4.8 \pm 1.1$ \\
Rasulpur & $35.2 \pm 2.6$ & $956.7 \pm 99.8$ & $7.3 \pm 2.3$ & $6.9 \pm 4.0$ & $5.6 \pm 2.0$ & $4.9 \pm 1.7$ \\
\hline
\end{tabular}

Table 2. Mean values and standard error of mean (SE) of neighbourhood based indices. Statistical tests were performed for the indices across different sample sizes. In all cases there were no significant differences across the different sample sizes (One-way ANOVA, $\mathrm{p}=0.05$ ).

\begin{tabular}{|c|c|c|c|c|c|c|c|c|c|c|c|c|}
\hline \multirow[b]{2}{*}{ Indices } & \multicolumn{6}{|c|}{ Rajabari } & \multicolumn{6}{|c|}{ Rasulpur } \\
\hline & All & $3 \mathrm{G} 5$ & $2 \mathrm{G} 5$ & $1 \mathrm{G} 5$ & $\mathrm{~F}$ & Sig.(p) & All & $3 \mathrm{G} 5$ & $2 \mathrm{G} 5$ & $1 \mathrm{G5}$ & $\mathrm{F}$ & Sig.(p) \\
\hline Mingling & - & $0.05 \pm 0.01$ & $0.05 \pm 0.01$ & $0.04 \pm 0.02$ & 0.24 & $\mathrm{~ns}(0.79)$ & - & $0.22 \pm 0.01$ & $0.20 \pm 0.01$ & $0.18 \pm 0.03$ & 0.83 & $\mathrm{~ns}(0.44)$ \\
\hline $\begin{array}{l}\text { Diameter } \\
\text { dominance }\end{array}$ & - & $0.49 \pm 0.03$ & $0.45 \pm 0.04$ & $0.43 \pm 0.05$ & 0.52 & $\mathrm{~ns}(0.60)$ & - & $0.43 \pm 0.02$ & $0.43 \pm 0.02$ & $0.46 \pm 0.05$ & 0.22 & $\mathrm{~ns}(0.80)$ \\
\hline Height dominance & - & $0.47 \pm 0.01$ & $0.44 \pm 0.03$ & $0.45 \pm 0.04$ & 0.12 & $\mathrm{~ns}(0.87)$ & - & $0.38 \pm 0.03$ & $0.38 \pm 0.03$ & $0.36 \pm 0.05$ & 0.50 & $\mathrm{~ns}(0.61)$ \\
\hline $\begin{array}{l}\text { Height } \\
\text { differentiation }\end{array}$ & - & $0.17 \pm 0.007$ & $0.17 \pm 0.007$ & $0.16 \pm 0.01$ & 0.26 & $\mathrm{~ns}(0.77)$ & - & $0.19 \pm 0.01$ & $0.19 \pm 0.01$ & $0.18 \pm 0.02$ & 0.09 & $\mathrm{~ns}(0.91)$ \\
\hline Contagion & - & $0.67 \pm 0.02$ & $0.66 \pm 0.02$ & $0.66 \pm 0.03$ & 0.05 & $\mathrm{~ns}(0.95)$ & - & $0.51 \pm 0.008$ & $0.51 \pm 0.008$ & $0.50 \pm 0.02$ & 0.10 & $\mathrm{~ns}(0.90)$ \\
\hline
\end{tabular}

All $=$ all tree, $3 \mathrm{G} 5=15$ trees, $2 \mathrm{G} 5=10$ trees and $1 \mathrm{G} 5=5$ trees from of a plot

Table 3. Size differentiation (Mean $\pm \mathrm{SD}$ ) among different species, based on $1 \mathrm{G} 5$ (5 trees/plot).

\begin{tabular}{lllll}
\hline Stand & \multicolumn{2}{l}{ DBH differentiation } & \multicolumn{3}{l}{ Height differentiation } \\
\cline { 2 - 5 } & Sal-Sal & Sal-other species & Sal-Sal & Sal-other species \\
Rajabari & $0.15 \pm 0.10$ & $0.18 \pm 0.09$ & $0.16 \pm 0.10$ & $0.20 \pm 0.12$ \\
Rasulpur & $0.15 \pm 0.13$ & $0.13 \pm 0.08$ & $0.17 \pm 0.15$ & $0.23 \pm 0.11$ \\
\hline
\end{tabular}

Table 4. Relationships $(\mathrm{Y}=\mathrm{a}+\mathrm{bX})$ between aggregation and dispersion of sal.

\begin{tabular}{lllll}
\hline Between & $a$ & $b$ & $r^{2}$ & $p$ \\
\hline Sal density $_{\text {alt tree }}-$ Contagion $_{5 \text { tree }}$ & 571.61 & 1369.4 & 0.25 & 0.00 \\
Sal proportion $_{\text {ell tree }}$-Contagion $_{5 \text { tree }}$ & 0.75 & 0.22 & 0.21 & 0.00 \\
\hline
\end{tabular}

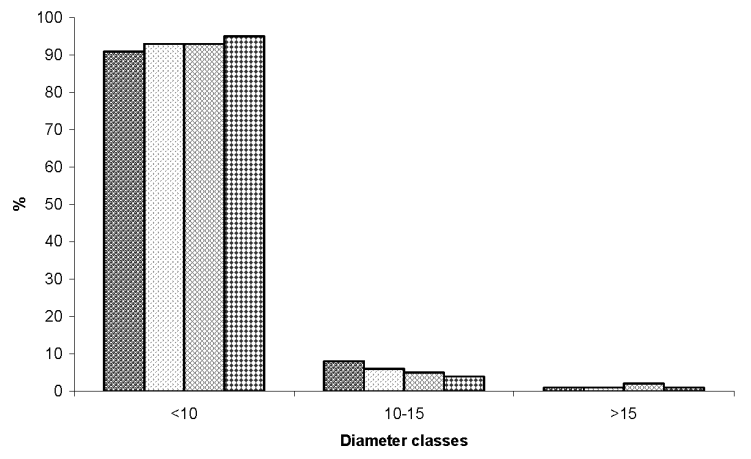

Figure 4. Diameter distributions of trees of both forests across different sample sizes.

stand in testing different sample sizes (Table 2) but there were some differences in median, quartiles, minimum and maximum values of indices observed across different sample sizes in both stands (Fig. 3). The highest standard error of mean was found in 1G5 followed by 2G5, 3G5 and the full sampling of all trees (Table 2). The boxplots also showed that the distribution of indices around the median values were most homogeneous in $3 \mathrm{G} 5$ followed by $2 \mathrm{G} 5$ and $1 \mathrm{G} 5$. These

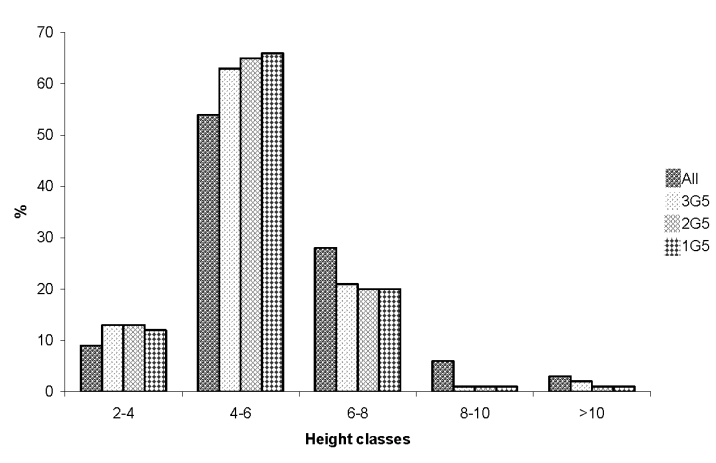

Figure 5. Height distributions of trees of both forests across different sample sizes.

plots indicate that with an increase of the number of sample trees the lower and upper quartiles of the calculated indicators has a tendency towards the median (Fig. 3).

\section{Discussion}

One objective of this contribution was to analyse the spatial diversity of the dominant tree species Shorea robusta for 
a better understanding of the ecology of the Madhupur sal forests. It was found that the mean value of mingling for sal indicated a high level of 'aggregation' of sal at both Rajabari and Rasulpur forests. A 'clumped' dispersion of trees was observed at Rajabari forest, while a 'random' dispersion was found at Rasulpur forest. With the increase of the proportion or the density of sal, the dispersion tended towards 'clumping' (Table 4). Tropical species with a low density tend to have relatively 'uniform' dispersion and those with high density have a 'clumped' dispersion (Krebs 1972). Sukumar et al. (1992) reported that with the increase of the abundance of deciduous species the clumping will increase. Rahman et al. (2007b) found a 'regular' dispersion of sal in forests existing 'lower aggregation' of sal. Shankar (2001) reported that the clumping of sal increased with its abundance. Sal is known as a dominant tree species in most of the forest ecosystems (Champion and Osmaston 1962, Troup 1986) and the tendency for clumping is related to the increase of its density and subsequently the dispersion changes from 'regular' to 'random' and 'random' to 'clumping'.

The size differentiation was higher between sal and other species than between the pairs of sal and sal, which indicates a relatively higher growth potential for sal in the young stages of stand development compared to the other species. Some authors have also found that the growth of sal is relatively faster than other species in the young development phases (Gautam and Devoe 2006).

Measures based on the nearest-neighbour concept allowed us to find no significant differences among different sample sizes according to both forest stands analyzed. However, dissimilarities were found for median, quartiles, minimum and maximum values. As the comparison of the neighbour-based spatial parameters are based on arithmetic mean values and some sort of scaling (Pommerening 2002), it is possible to find non significant differences across different sample sizes in both forest stands, although the median and quartiles of the single values indicate some small differences. Considering the mean values the least sample size (5 trees/plot) measured unique spatial characteristics in both stands.

The study aimed to assess the applicability of neighbourhood analysis in the sal forests of Bangladesh and to find out a suitable setting for the design of the fieldwork of the structural analysis based on the number of reference trees. It was found that using 5, 10 and 15 trees from each plot has no significant effect on the results based on mingling, size dominance, size differentiation and contagion. The proportion of sal obtained from the mingling values across 5, 10 and 15 tree per plot, showed similar results compared to the full sampling of all trees on the plot. So, it can be assumed that using the mingling index of the neighborhood analysis can be used to describe the species composition of the sal forests reasonably well. Single G5 (5 trees/plot) approach could be used to measure the horizontal and vertical structure of a forest instead of 3G5 (15 trees/plot). However, the number of individuals in lower height classes would be overestimated. This fact might also be linked to the problem that some neighbouring trees for the third or the most distant reference tree came from outside of the plot area, which may not have been part of the full sample on the circular plot. However, a single G5 ( 5 trees) from each plot may be efficiently used to measure structural (composition, horizontal and vertical structure) and spatial (dispersion, aggregation and size differentiation) parameters of a forest, saving money and time simultaneously.

According to the selection process for the reference tree, we adopted a new approach. We took 3 reference trees on the basis of the distance from the centre of the $300 \mathrm{~m}^{2}$ circular plot (first: the nearest from the centre, second: the nearest from the middle point of the radius and the third: the most distant from the centre). This procedure allowed reducing a bias from the effect of selecting a reference tree. It would be difficult to examine many reference trees with their neighbours, maintaining an equal distance from the centre of a circle of $300 \mathrm{~m}^{2}$ area to each neighbours.

These neighbourhood-based variables and methods can be used in the field at low cost and less time to describe, compare and evaluate forest structure in a scientifically sound way. During field work, there is no need to consider the tree coordinates or the distances between trees to evaluate the basic spatial characteristics. The two young forests considered in this study were more or less homogeneous and highly sal dominant. Further research is needed for more heterogeneous and highly mixed forests to justify the applicability of these neighbourhood indices. However, considering its simplicity, we can recommend adopting the method with one "group of five" (G5) to measure the structural and spatial diversity of young and homogeneous sal forests of Bangladesh in the context of an inventory based on a regular grid or transects.

Acknowledgements: We would like to convey our heartiest thanks Madhpur sal forest authority, Bangladesh for their immense help during data collection and would like to extend our gratitude to Austrian Development Cooperation (OEAD) for patronizing financial support. We thank Mrs. S. Biswas for her support in data entry.

\section{References}

Aguirre, O., G.Y. Hui, K. Gadow and J. Jiménez. 2003. An analysis of spatial forest structure using neighbourhood-based variables. Forest Ecol. Manage. 183: 137-145.

Alam, M.K. 1995. Diversity in the woody flora of sal forests of bangladesh. Bangladesh J. Forest Sci. 24(1): 41-52.

Albert, M. 1999. Analyse der eingriffsbedingten Strukturveränderung und Durchforstungsmodellierung in Mischbeständen. Ph.D. Dissertation, Faculty of Forest Sciences, University Göttingen. Hainholz, Germany. pp. 63-68.

Banglapedia. 2006. Sal forest. National Encyclopedia of Bangladesh.

Champion, H. and F.C. Osmaston (eds). 1962. E. P.Stebbing's The Forests of India, vol. IV. Oxford University Press, London.

Clark, P.J. and F.C. Evans. 1954. Distance to nearest neighbour as a measure of spatial relationships in populations. Ecology 35:445-453. 
Füldner, K. 1995. Strukturbeschreibung von Buchen-EdellaubholzMischwäldern. [Describing forest structures in mixed beechash-maple-sycamore stands.] PhD dissertation, University of Göttingen, Cuvillier Verlag Göttingen.

Gadow, K. v. and G.Y. Hui. 2002. Characterising forest spatial structure and diversity. In: L. Bjoerk (eds), Sustainable forestry in temperate regions. Proceedings of the IUFRO International Workshop. Lund, Sweden, pp. 62020-30.

Gadow, K.v., G.Y. Hui and M. Albert. 1998. Das Winkelmaß - ein Strukturparameter zur Beschreibung der Individualverteilung in Waldbeständen. [The uniform angle index - a structural parameter for describing tree distribution in forest stands.] Zentralblatt für das gesamte Forstwesen 115(1):1-10.

Gain, P. 1998. The Last Forests of Bangladesh. Society for Environment and Human Development (SEHD), Dhanmondi, Dhaka, Bangladesh.

Gautam, K.M. and N. Devoe. 2006. Ecological and anthropogenic niches of sal (Shorea robusta Gaertn. f.) forest and prospects for multiple-product forest management - a review. Forestry 79(1): 81-101.

Graz, F.P. 2006. Spatial diversity of dry savanna woodlands: Assessing the spatial diversity of a dry savanna woodland stand in northern Namibia using neighbourhood-based measures. Biodiversity and Conserv. 15:1143-1157.

Hui, G.Y., M. Albert and K.v. Gadow. 1998. Das Umgebungsmaß als Parameter zur Nachbildung von bestandesstrukturen. Forstwissenschaftliches Zentralblatt 117:258-266.

Islam, K.K., M.A.R. Khokon, M.J. Pervin, M.M. Rahman and H. Vacik. 2007. Prevalence of ectomycorrhizal fungi in Madhupur Sal forest of Bangladesh. J. Agroforestry Environ. 1: 27-30.

Ismail, M. and M.M.K. Mia. 1973. Studies on some deciduous 'sal' forests of Bangladesh. Ecology of Bangladesh vegetation, No.2. Department of Botany, University of Dhaka, Bangladesh, pp. 79-103.

Krebs, C.J. 1972. Ecology. The Experimental Analysis of Distribution and Abundance. Harper \& Row, New York.

Nishat, A., S.M. Huq, Imamul, Barua, P. Shuvashish, Reza, A.H.M. Khan and A.S. Moniruzzaman. 2002. Bio-ecological Zones of Bangladesh. IUCN Bangladesh Country Office, Dhaka, Bangladesh, pp. 54-55.

Pielou, E.C. 1977. Mathematical Ecology. Wiley, New York.

Pommerening, A. 1997. Eine Analyse neuer Ansätze zur Bestandesinventur in strukturreichen Wäldern [An analysis of new approaches towards stand inventory in structure-rich forests]. Ph.D. dissertation, Faculty of Forestry and Forest Ecology, University of Göttingen, Cuvillier Verlag Göttingen, pp. 187.
Pommerening, A. 2002. Approaches to quantifying forest structures. Forestry 75:305-324.

Pretzsch, H. 2001. Modellierung des Waldwachstums. Parey Buchverlag, Berlin.

Rahman, M.M., F. Begum, A. Nishat, K.K. Islam and H. Vacik. 2007a. Comparison of structural diversity of tree-crop associations in peripheral and buffer zone of Gachabari Sal Forest Area, Bangladesh. J. Forestry Res. 18:23-26.

Rahman, M.M., A. Nishat, G.M.M. Rahman, H. Ruprecht and H. Vacik. 2007b. Neighbourhood analysis of Sal (Shorea robusta Gaertn.f) in near natural and coppiced Sal forests at Madhupur, Bangladesh. In: Italian Academy of Forest Science (ed.), $2^{\text {nd }}$ International Nearest Neighbors workshop. Florence, Italy, pp. 38.

Richards, B.N. and M.M. Hassan. 1988. A coordinated forest soils research programme for Bangladesh, Working Paper No.4. Second Agricultural Research Project (Forestry Sector), UNDP/FAO Project BGD/83/010.

Shankar, U. 2001. A case of higher tree diversity in a sal (Shorea robusta)-dominated lowland forest of Eastern Himalaya: Floristic composition, regeneration and conservation. Current Science 81: 776-786.

Staupendahl, K. 2001. Das flächenbezogene Winkelmass Wf-Ein Index zur quantitativen Beschreibung der horizontalen Baumverteilung. In: Akca, A. et al. (eds.). Waldinventur, Waldwachstum und Forstplanung-Moderne Technologien, Methoden und Verfahrensweisen. Festschrift K. von Gadow. Zohab, Göttingen, pp. 101-115.

Stoyan, D.U. and H. Stoyan. 1992. Fraktale Formen Punktfelder. Methoden der Geometrie-Statistik. Akademie, Berlin.

Sukumar, R., H.S. Dattaraja, H.S. Suresh, J. Radkhakrishnan, R. Vasudeva, S. Nirmala and N.V. Joshi. 1992. Long-term monitoring of vegetation in a tropical deciduous forest in Mudumalai, Southern India. Current Science 69: 608-616.

Troup, R.S. 1986. The Silviculture of Indian Trees. International Book Distributors, Dehradun, India.

Webb, E.L and R.N. Sah. 2003. Structure and diversity of natural and managed sal (Shorea robusta Gaertn.f.) forest in the Terai of Nepal. Forest Ecol. Manage. 176: 337-353.

Zenner, E.K. and D.E. Hibbs. 2000. A new method for modeling the heterogeneity of forest structure. Forest Ecol. Manage. 129(1): 75-87. Received January 31, 2008
First revison June 16, Second revision August 13, 2008 Accepted October 20, 2008 